\section{Response to: 'Obesity and comorbidity are independently associated with a failure to achieve remission in patients with established rheumatoid arthritis' by Ellerby et al}

We thank Ellerby et $a l^{1}$ for their interest in our manuscript addressing the effect of obesity on the prognosis of rheumatoid arthritis (RA), and for sharing their own data. We are happy to see Ellerby and colleagues' findings in the later phase of RA to be in accordance with our own findings in early $\mathrm{RA}^{2}$ and to confirm findings by Ajeganova et $a l^{3}$ who have shown a similar effect of obesity in patients with longstanding RA. We are, as Ellerby and colleagues are, also very interested in the underlying biological mechanism for these findings. Further, we look forward to upcoming initiatives to clinically study whether this link between obesity and decreased chance of good response and remission can be countered by a voluntary weight decrease during the disease course.

\section{Maria E C Sandberg, ${ }^{1}$ Camilla Bengtsson, ${ }^{1}$ Henrik Källberg, ${ }^{1}$ Annmarie Wesley, ${ }^{1}$ Lars Klareskog, ${ }^{2}$ Lars Alfredsson, ${ }^{1}$ Saedis Saevarsdottir ${ }^{1,2}$}

${ }^{1}$ Department of Environmental Medicine, Karolinska Institutet, Stockholm, Sweden 2Department of Rheumatology, Karolinska Institutet, Stockholm, Sweden

Correspondence to Dr Maria E C Sandberg, Department of Environmental Medicine, Karolinska Institutet, Nobelsv. 13, Stockholm 171 77, Sweden; maria.sandberg@ki.se

Contributors LA and SS contributed equally.

\section{Competing interests None.}

Provenance and peer review Commissioned; internally peer reviewed.

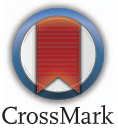

To cite Sandberg MEC, Bengtsson C, Källberg H, et al. Ann Rheum Dis 2014;73 e79.

Received 13 August 2014

Revised 20 August 2014

Accepted 12 September 2014

Published Online First 26 September 2014

\section{Sinked}

http://dx.doi.org/10.1136/annrheumdis-2014-206254

http://dx.doi.org/10.1136/annrheumdis-2013-205094

Ann Rheum Dis 2014;73:e79. doi:10.1136/annrheumdis-2014-206369

\section{REFERENCES}

1 Ellerby N, Mattey DL, Packham J, et al. Obesity and comorbidity are independently associated with a failure to achieve remission in patients with established rheumatoid arthritis. Ann Rheum Dis 2014;73:e74.

2 Sandberg ME, Bengtsson C, Kallberg $H$, et al. Overweight decreases the chance of achieving good response and low disease activity in early rheumatoid arthritis. Ann Rheum Dis 2014;73:2029-33.

3 Ajeganova S, Andersson ML, Hafstrom I. Association of obesity with worse disease severity in rheumatoid arthritis as well as with comorbidities: a long-term followup from disease onset. Arthritis Care Res (Hoboken) 2013;65:78-87. 